\title{
LA JUSTICIA LIBERAL Y LA SEXUALIDAD HUMANA
}

\author{
THE LIBERAL JUSTICE AND HUMAN SEXUALITY
}

\begin{abstract}
Alessandro Caviglia Marconi*
RESUMEN

El presente trabajo explora la relación entre las mujeres, las minorías sexuales y el acceso a la justicia desde la perspectiva del liberalismo político contemporáneo de John Stuart Mill, Michael Walzer, John Rawls y Martha Nussbaum y la perspectiva postsocialista de Nancy Fraser. En este sentido se distancia tanto del enfoque de la llamada tercera ola del feminismo, porque rechaza su centralidad en la identidad y en la diferencia de base biologicista, como también se separa del enfoque liberal clásico que define los términos de la justicia sin tener en cuenta las voces de los sujetos implicados. Al mismo tiempo explora la constitución de la sexualidad humana desde una perspectiva hermenéutica y busca establecer las bases para la justicia sexual.
\end{abstract}

\section{PALABRAS CLAVE}

Feminismo, liberalismo político, sometimiento de las mujeres, esclavismo, minorías sexuales, justicia sexual.

\begin{abstract}
The present paper explores the relationship among women, sexual minorities and the access to justice from the perspective of contemporary political liberalism of John Stuart Mill, Michael Walzer, John Rawls and Martha Nussbaum and the post-socialist prospect of Nancy Fraser. In this sense is detached from both the approach of the so-called third wave of feminism, because it rejects its centrality in the identity and the difference in biological basis, and the classical liberal approach that defines the terms of the justice without taking into account the voices of the subjects involved. At the same time, it explores the constitution of human sexuality from a hermeneutical perspective and seeks to establish the bases for sexual justice.
\end{abstract}

\section{KEY WORDS}

Feminism, political liberalism, subjugation of women, slavery, sexual minorities, sexual justice.

* Docente de la Universidad Antonio Ruiz de Montoya: ascavilgia@yahoo.com 


\section{INTRODUCCIÓN}

La discusión en torno a en qué modo y cuánto se está haciendo justicia con las mujeres ha estado dominada por la teoría social, la psicología y la filosofía feminista, las cuales han tenido como agenda 1) el cuestionamiento de la racionalidad, 2) poner en primer plano las diferencias psicológicas entre hombres y mujeres y 3) colocar el discurso sobre la justicia liberal a los márgenes del debate. El cuestionamiento de la racionalidad se basa en la acusación de que la racionalidad dominante en los foros académicos es la racionalidad occidental centrada en el varón, caracterizada por la preeminencia del pensamiento abstracto. En este sentido, se arguye que la mujer usa otros parámetros de racionalidad que se relacionan más con lo concreto, y el cuidado de los demás y de la naturaleza. Este argumento se basa en la idea de que las mujeres tienen una estructura psicológica diferente a la de los hombres, de modo que la mujer es radicalmente distinta al varón pero al mismo tiempo ambos sexos son complementarios. Finalmente, puesto que el modelo liberal de justicia se encuentra articulado conforme a los parámetros de la "racionalidad moderna falocéntrica", la teoría feminista señala que hay que rechazar dicho modelo'.

El postmodernismo que se destila de esta teoría feminista puede resultar sumamente conveniente para quienes quieran hacer a un lado la justicia política de la reflexión sobre la mujer y destacar la idea de complementariedad asimétrica entre los sexos, que termina justificando el acceso desigual a la justicia. Contra esta pretensión, el liberalismo político ha estado articulando una reflexión respecto de la justicia política y social de la mujer, la que se nutre de las ideas que John Stuart Mill presentó en su célebre tratado $\mathrm{El}$ sometimiento de las mujeres y por los aportes que John Rawls ha hecho a la teoría política y jurídica. En lo que sigue presentaré algunos de los elementos centrales de la reflexión que desde el liberalismo político se hace respeto de la justicia a la mujer. Como este tema se entronca al interior de la justicia sexual, será necesario complementar nuestra reflexión con una visión respecto de la justicia sexual en general.

En el fondo, es posible destacar tres maneras de enfocar la justicia para con la mujer: a) el enfoque feminista biologicista y psicologista, b) el enfoque liberal clásico y c) el enfoque del liberalismo político contemporáneo. El primero considera que las diferencias biológicas y psicológicas son determinantes al momento de reflexionar sobre la justicia. Este enfoque se encuentra representado por las posiciones que he esbozado arriba. El enfoque liberal clásico aboga por la imposición de un esquema universal de derechos y libertades igualitarios, pensado desde los hombres y que no toma en cuenta la voz de las mujeres. En cambio, el enfoque del liberalismo político contemporáneo va construyendo un esquema de derechos y libertades igualitarios tomando en cuenta la voz de las mujeres. En este sentido Richard Rorty señala que:

1 Al respecto Cf. BENHABIB, Sheyla (2006). Además GILLIGAN, Carol (1996). El trabajo de Gilligan se presenta como una respuesta, desde la perspectiva femenina, a la teoría del desarrollo moral planteado por Lawrence Kohlberg, la cual es acusada de estar centrada en el desarrollo masculino y enfatiza la configuración de conceptos abstractos y una moral de corte universalista. El trabajo de Gilligan resulta interesante, pero parte de un presupuesto que hay que comenzar por demostrar si es verdadero. Dicho presupuesto supone que es posible extraer consideraciones morales partiendo de hechos fácticos, como las diferencias biológicas entre el varón y la mujer. La complicación de la argumentación de Gilligan es la misma que tuvo en su tiempo la llamada Teoría crítica de la sociedad desarrollada por la escuela de Fráncfort, complicación que llevó al descrédito de las propuestas desarrolladas por dicha escuela de estudios sociales. Sobre los problemas conceptuales de la Teoría crítica véase TUGENDHAT, Erns (1997). 
"Los filósofos universalistas dan por hecho con Kant que al día de hoy está disponible todo el espacio lógico necesario para la deliberación moral, que todas las verdades más importantes sobre lo que está bien y lo que está mal puede, no sólo formularse, sino también hacerse plausibles con el lenguaje con el que ya contamos. En cambio... [los] filósofos historicistas como Hegel y Dewey... [afirman] que el progreso moral depende de que se expanda ese espacio. La necesidad de dicha expansión queda bien ilustrada cuando apunta que la actual ley sobre discriminación sexual supone que las mujeres -han de ajustarse, o bien a los estándares masculinos para los varones, o a los estándares masculinos para las mujeres...A los efectos de la ley sobre discriminación sexual, ser una mujer significa ser como un hombre o ser como una dama-" (Rorty, 200, p. 224).

\section{1.- LIBERALISMO POLÍTICO JUSTICIA SEXUAL}

El liberalismo político es una corriente de pensamiento político que hunde sus raíces en el siglo XVII y que ha ido ganando una mayor articulación y presencia en el ámbito del pensamiento político a través de los aportes de John Locke, Immanuel Kant, John Stuart Mill, Isaiah Berlin, John Rawls, John Gray, Michael Walzer, Richard Rorty y Martha Nussbaum, entre otros intelectuales importantes.

Una de las descripciones más exitosas de la cultura política liberal es la presentada por Walzer. Según esta descripción, el mundo liberal es un mundo en el que se levantan muros simbólicos que separan las diferentes instituciones de la sociedad. De esta manera, la esfera del Estado y la esfera de la Iglesia cobran independencia una de la otra. Esto hace que los bienes, tanto materiales como no materiales, se generen, adquieran significado y se distribuyan de acuerdo a la lógica de cada esfera. Así, el Estado genera, da significado y distribuye bienes como el poder político de acuerdo a procedimientos internos a la lógica de la institución estatal. Estos procedimientos pueden ser el voto de los ciudadanos, para elegir al Presidente de la República y los congresistas, y el mérito para la elección de ministros y asesores de gobierno. Algo análogo ocurre con la distribución de bienes que circulan en la Iglesia. En este caso se trata de la salvación y los sacramentos, en tanto medios para la salvación, que son distribuidos por sacerdotes de acuerdo a los criterios apropiados, criterios determinados al interior de la Institución.

Ambas instituciones son independientes una de la otra, de modo que los criterios del poder político no interfiere en la Iglesia, ni los criterios propios de la salvación determina el funcionamiento del Estado. Esto hace posible el surgimiento de un conjunto de libertades, como es la libertad de creencia religiosa, la libertad de conciencia, la libertad de expresión, entre otras. Cuando una esfera interfiere en otra, imponiéndole su lógica, se produce lo que Walzer (2010) -retomando la idea de Locke - denomina tiranía. En este sentido, la política liberal tiene como objetivo ampliar el ámbito de las libertades y el combate de las tiranías. Con el tiempo, otras instituciones se fueron abriendo paso en esta diferenciación de esferas, como son la sociedad y el mercado, la familia, y aquellas que tiene que ver con la educación, la seguridad, la salud, entre otras. Y dicho despliegue sigue desarrollándose, de modo que hoy siguen diferenciando esferas y abriéndose paso a nuevas libertades. 
John Rawls (1996) acertó al complementar esta descripción del liberalismo con la distinción entre lo público o político y lo privado o doméstico. Si bien lo público es prioritariamente lo estatal y los principios de justicia política, se asocian al ámbito de las políticas públicas también. Lo privado o doméstico, en cambio, tiene que ver con grupos que tienen una concepción del bien y que se encuentran en el ámbito de la sociedad. De esta manera tanto el Estado como las instituciones de salud, educación y seguridad pública se encuentran en el ámbito de lo político, en cambio instituciones como el mercado, la familia y las iglesias, entre otras, se encuentran en el ámbito de lo doméstico. Ciertamente, las iglesias pueden hacer valer su voz en la esfera pública a través de lo que Rawls (2001) denomina estipulación, señalando que "en el debate político público se pueden introducir, en cualquier momento, doctrinas generales razonables, religiosas y no religiosas, siempre que se ofrezcan razones políticas apropiadas - y no sólo razones derivadas de las doctrinas - para sustentar lo que ellas proponen" (Rawls, 2001, p. 177).

Esta ubicación de las esferas realizada por Rawls (2001) permite precisar las reflexiones respecto de la relación entre la justicia liberal y las mujeres. Instituciones como la familia y las iglesias resultan claves para la realización de la justicia con la mujer. En la familia la relación que establece la mujer ya sea con el esposo, los padres o los hermanos varones resulta determinante para que pueda acceder a la justicia tanto en esa esfera como en las demás. En las iglesias, las relaciones que pueden abrir o cerrar el acceso a la justicia a las mujeres es aquella que establecen con las autoridades eclesiales.

\section{2.- ESCLAVISMO Y SOMETIMIENTO DE LA MUIER}

En su clásico libro titulado El sometimiento de las mujeres John Stuart
Mill abre una reflexión sistemática y seria respecto de la justicia para con las mujeres. El texto de Mill ha servido como base para el movimiento de reivindicación de derechos de la mujer y contiene un hilo argumentativo claro. De acuerdo a Mill, sucede que denominamos "naturales" opiniones que se encuentran muy arraigadas en nuestra conciencia como sociedad, de tal manera que consideramos que dichas opiniones describen la naturaleza del mundo, de las personas y de las relaciones sociales. Pero lo que sucede en el fondo es que dichas opiniones, en vez de describir las cosas tal como son lo que hacen realmente es expresar nuestras creencias respecto de la realidad, lo cual es un indicio de que ellas podrían modificarse.

Más aún, el autor constata que cuando un sentimiento se encuentra arraigado profundamente en las personas, las razones y los argumentos no surten efecto en la remoción de opiniones y prejuicios. De modo que:

"Siempre que una opinión
está arraigada con fuerza en los sentimientos, el peso preponderante de los argumentos en su contra le añade estabilidad, más que quitársela. Pues, si la opinión estuviera aceptada como consecuencia de unos argumentos, la refutación de los argumentos podría hacer vacilar la solidez de la convicción; pero cuando esta se apoya únicamente en los sentimientos, cuanto peor parada sale de lo los debates polémicos, más convencidos quedan sus partidarios de que su sentimiento debe apoyarse en unas bases más hondas a las que no alcanzan los argumentos; y mientras persista el sentimiento, no deja jamás de acudir con argumentos nuevos a reparar las brechas que hayan 
podido sufrir los antiguos" (Mill, 2005, p. 72).

Lo que Mill señala es que las opiniones sobre la esclavitud, la sumisión de la mujer y la sexualidad humana no se basan en datos biológicos y no describen nuestra propia naturaleza, sino que son una construcción social. Quien indicó esto de manera más clara fue Michel Foucault, pero asoció su observación a una política radical dirigida a subvertir nuestros juicios morales. Sin embargo, es posible asumir la teoría de la construcción social de la sexualidad sin comprometerse con la agenda radical de Foucault y los postmodernos, sino asumiendo una agenda reformista que no atente contra la capacidad de deliberar razonablemente respecto de los temas en cuestión. Volveré más adelante sobre este asunto.

Durante mucho tiempo sucedió en occidente y en otras partes del mundo que se creía que la esclavitud era algo natural, y que estaba plenamente justificado sancionar legalmente la relación amo - esclavo. Sin embargo, a mediados del siglo XIX dicha creencia comenzó a resquebrajarse, y se dio un proceso social y político que fue terminando con la esclavitud de los negros en occidente. La cristalización de dicho proceso fue la Guerra de Secesión Norteamericana (1861 - 1865) en la que Abraham Lincoln tuvo un papel determinante. Más allá del hecho de que los intereses económicos del norte industrializado se contrapusiesen a los del sur básicamente rural, lo sucedido en la Guerra Civil Norteamericana es que la creencia en la esclavitud de los negros fue, de una u otra manera, derrotada, y se instauró en el sistema legal la creencia en la igualdad entre negros y blancos. Ciertamente, la derrota en el campo social de la creencia de la superioridad de la raza blanca sobre la negra fue vencida en los Estado Unidos de América un siglo después, con la lucha por los derechos civiles dirigida por el Dr. King y otros. El hecho de que el triunfo de la igualdad en el ámbito social se dé un siglo después del triunfo de la igualdad en el ámbito político y legal expresa, entre otras cosas, el que las ideas de una sociedad no cambian con la velocidad con la que pueden cambiar las leyes, y ciertas prácticas sociales se mantienen aún durante un tiempo prolongado porque los cambios de mentalidad son lentos.

En este proceso resultó de mucha importancia la participación de los negros, tanto durante la Guerra de Secesión, como en el movimiento por los derechos civiles de la segunda mitad del siglo XX. Durante la Guerra de Secesión los negros participaron en el ejército de la Unión, que representaba a los Estados del Norte, frente al ejército de los Estados Confederados de América, que representaba a los Estados del Sur. Un ejemplo de ello es el $54^{\circ}$ Regimiento de Infantería de Voluntarios de Massachusetts, organizado en Marzo de 1863. Igualmente, durante la lucha por los derechos civiles fue decisiva la participación de los negros. Por ejemplo, Rosa Parks, quien se convirtió un ícono de este movimiento al negarse a ceder el asiento a un blanco en un bus y sentarse al final del vehículo en Montgomery, Alabama el $1^{\circ}$ de diciembre de 1955. En 1950, ella se unió al Movimiento por los Derechos Civiles. De esta marea el proceso de reconocimiento de los derechos de los negros en Estados Unidos expresó la voz de los mismos involucrados (Bender, 2011).

El proceso por el que se ha reconocido la igualdad legal, política y social de la mujer frente al varón ha sido análogo a aquél que terminó con la esclavitud. Aunque se trata de un fenómeno posterior, la lógica fue la misma: vencer unas opiniones ancladas en la conciencia de las personas en occidente de que 
apuntan a considerar verdadera la creencia de que el hombre es superior a la mujer y ello debe traducirse en los códigos legales, sancionando la negativa al voto a las mujeres o la prohibición al acceso a la educación o a la participación en la vida pública de la sociedad sea por medio del trabajo o por la actividad política. Pero la situación de la mujer, tal como lo señala acertadamente Mill (2005), es peor que la del esclavo durante la primera mitad del siglo XIX. Mientras que el esclavo se encuentra junto a su amo en algunos momentos del día, pero no en la cama mientras duerme, la mujer llega a dormir al lado de su "amo". En otras palabras, la sujeción de la mujer al varón es mayor que la que sufre el esclavo frente al amo. Pero en ambos casos dicha sujeción se fundamente en una supuesta naturaleza humana. Y, al igual que con el caso de la supresión de la esclavitud, para que el sometimiento de la mujer al varón sea combatido plenamente no basta con la legislación, sino que es necesario una educación en la sociedad para que ciertas prácticas vayan quedando en el pasado.

Mill describe la situación de la mujer, señalando que en la antigüedad:

"La propia Iglesia cumplía con una moral superior requiriendo que la mujer pronunciara expresamente un 'sí' en la ceremonia del matrimonio; pero no había nada que demostrara que aquél consentimiento no fuera forzado; y a la muchacha le resultaba prácticamente imposible negarse a aceptar si el padre se empeñaba, salvo quizá en casos en que ella pidiese acogerse a la protección de la religión manifestando su deseo firme de tomar los votos y hacerse monja. Después del matrimonio, igualmente, el marido tenía derecho de vida o muerte sobre su esposa. Ella no podía recurrir a ninguna ley contra él: él era su única ley y tribunal. Durante mucho tiempo el marido pudo repudiarla sin que ella tuviese la misma capacidad respecto de él" (Mill 2005, p. 122).

Y sigue retratando, ya no la condición de la mujer en las épocas anteriores a su época, sino, las que están vigentes durante la segunda mitad del siglo XIX, con estas palabras

"En vistas de que estas diversas monstruosidades han quedado en desuso los hombres suponen que el contrato matrimonial ya es todo como debe ser; y se nos dice constantemente que la civilización y el cristianismo han devuelto a la mujer sus justos derechos. Mientras tanto, la esposa es una verdadera esclava del marido, y no en menor medida, en lo que a las obligaciones legales, que los esclavos a los que no suele dar comúnmente el nombre de tales. En el altar le jura obediencia perpetua, y la ley le obliga a mantenerla mientras le dure la vida....La mujer no puede realizar acto alguno más que con permiso de su marido, al menos tácito. No puede adquirir ninguna propiedad si no es para él; en el momento mismo en que ella adquiere algún bien, pasa a ser de él automáticamente" (Mill 2005, p. 123).

Y un poco más abajo, muestra cómo la condición de la mujer es peor que la del esclavo:

"No quiero decir, ni mucho menos, que en general se trate a las esposas peor que a los esclavos; pero ningún esclavo es tan esclavo, en el sentido pleno de la palabra, como lo es la esposa para el marido. Casi ningún 
esclavo, salvo alguno que ejerza de criado o custodio personal del amo, es esclavo a todas horas y a cada minuto; en general suelen tener, como los soldados, una tarea fija, y cuando la han realizado o cuando no está de servicio, puede disponer de su tiempo libre dentro de ciertos límites, y hace una vida familiar en la que rara vez se entromete el amo. El 'tío Tom', bajo su primer amo, tenía su 'cabaña' en la que hacía su propia vida, casi como cualquier hombre que vuelve a su casa y con su familia después del trabajo. Sobre todo, la esclava tiene un derecho reconocido (en los países cristianos), y se le considera sometida a la obligación moral de negar a su amo la mayoría de las familiares. No así la esposa: por muy brutal que sea el tirano al que tiene la desventaja de estar encadenada (aunque ella sepa que la odia, aunque él se complazca diariamente en atormentarla, y aunque a ella le resulte imposible dejar de aborrecerlo), el marido puede exigirle y obligarle a someterse a la más baja de las degradaciones de un ser humano, la de servir de instrumento de una función animal opuesta a sus inclinaciones. Mientras la esposa se ve sometida en su propia persona a esta esclavitud, la peor de todas, ¿cuál es su situación en lo que respecta a los hijos que tienen en común su amo y ella. Por ley, los hijos son de él. Solo él tiene derechos legales sobre ellos" (Mill 2005, pp. 125-126).

Me he permitido citar extensamente el texto de Mill, porque la viveza de su descripción grafica con claridad la situación en la que la mujer vivía durante su época y antes del siglo XIX. Podríamos señalar que las condiciones de vida de las que gozan las mujeres en la actualidad han dejado en el recuerdo aquél retrato que el filósofo inglés nos presenta. Hoy las mujeres gozan de las libertades y derecho que sus antepasadas ni soñaron llegar a gozar. Muchas de ellas son profesionales destacadas, jefes de estado y líderes importantes. Pero no hemos de dejar de ver que en ciertos sectores urbanos de las ciudades de todo el mundo, y en la mayoría de las zonas rurales, la situación no ha mejorado sustantivamente. La falta de libertades de muchas mujeres se encuentra asociada a la ausencia de acceso a la educación que le permita tener acceso a la información relevante respecto de los accesos que podrían activar para revertir la situación a las que parecen estar destinadas. Prácticas como el acoso sexual al paso, en la calle, el acoso en el trabajo y la violación dentro de la familia son algunos de los daños físicos, psíquicos y morales que las mujeres siguen sufriendo en nuestros días. La tasa de feminicidio es alarmantemente alta en todo el mundo.

Si en tiempos de paz la situación de muchas mujeres es peor que la de los varones, en tiempo de conflictos armados ellas llevan siempre la peor parte. Ello ha sido claro durante el conflicto armado interno que se vivió en Perú entre el 80 y el 2000. No hay conflicto armado en el que la práctica de la violación y el sadismo sexual no esté presente, lo que hace a las mujeres más vulnerables que los varones. En Perú, el sector más vulnerable respecto a la violencia ha sido el de personas que conjugaban estos tres rasgos: quechua o aymarahablante, campesino y mujer. Y la violencia venía tanto de parte de de Sendero Luminoso y el MRTA, como de las Fuerzas Armadas

\section{3.- LAS MUJERES Y LOS DERECHOS EN LAS INSTITUCIONES POLÍTICAS}

El reconocimiento de las mujeres en el plano político supone una actividad 
en tres áreas: a) en la legislación, b) en las instituciones públicas y c) gozar del derecho de deliberación sobre las políticas públicas. En el plano de la legislación el reconocimiento se expresa en las leyes jurídicas que suprimen el sometimiento de la mujer al varón y que reconocen la igualdad legal de hombres y mujeres. En este sentido encontramos una política de reconocimiento de derechos políticos iguales, como son el derecho al voto, el derecho a ser elegidas y a participar en la deliberación sobre temas públicos desde la sociedad civil, en igualdad de condiciones que el varón, entre otros derechos. Además, el reconocimiento de derechos civiles iguales como el derecho al matrimonio, a profesar la religión de su preferencia, el derecho de expresión de sus ideas y el derecho a la integridad física y psicológica, entre otros. Al mismo tiempo, encontramos la exigencia del reconocimiento de la igualdad de derechos sociales, como el derecho a una salud de calidad, el derecho a la educación y a la seguridad. Al mismo tiempo, derechos económicos como el derecho a participar libremente en el mercado y a ingresar al mercado laboral bajo condiciones de justa igualdad de oportunidades. El derecho al trabajo supone, claro está, el de recibir una justa remuneración por el trabajo realizado y el de contar con seguridad social dentro del trabajo.

La igualdad política de la mujer frente al varón en las instituciones públicas se expresa en igualdad de trato y consideración en tres situaciones: al postular a un puesto en el Estado, en el desempeño de su trabajo en cuanto funcionaria estatal y en cuando ciudadana que acude a los servicios o a cumplir con sus obligaciones frente al Estado. Así, al postular a un puesto en el Estado, se debe tener en cuenta sólo el criterio de discriminación por mérito, pero no por sexo. Así, para acceder a puestos que van desde ministras de gobierno hasta empleadas públicas de mediano y bajo rango, las mujeres deben encontrarse en igualdad de condiciones que los varones, teniendo en cuenta únicamente la capacitación de la persona en cuestión. Esto debería de incluir una ley de cuotas bajo la forma de una política afirmativa que permita hacer justicia frete a la discriminación surgida durante siglos. De la misma manera, una vez que la mujer accede a una contratación en el Estado, debe gozar de los mismos derechos que los varones, especialmente el de su integridad física. Y en cuanto a ciudadana que acude a las instituciones públicas a fin de acceder a los servicios del Estado, las mujeres deben de ser tratadas con igual consideración, pero además deben de acceder a la información relevante que les permita activar los servicios de tales instituciones.

En lo que se refiere a la capacidad de deliberación de las mujeres respecto de cuestiones públicas, es claro que esto permite hacer oír la voz de las mujeres para modelar las instituciones políticas, pero para que ello sea posible es necesario que se abran espacios de deliberación que permitan incluir sus voces y además las mujeres requieren recibir una educación que las dote de criterios de información relevantes para evaluar y examinar la situación de sus localidades, y la de la sociedad y el país en el que viven. Al respecto, Martha Nussbaum (2012) sobre la necesidad de crear capacidades en las mujeres para el desarrollo humano.

\section{4.- LAS MUJERES Y LOS DERECHOS EN LAS INSTITUCIONES SOCIALES}

Pero no sólo es necesario garantizar la justicia de las mujeres dentro de las 
instituciones públicas, sino también hay que considerar las condiciones que permitan que ello sea posible dentro de las instituciones sociales, como los colegios profesionales, los clubes, y especialmente la familia y las iglesias. Respecto de la familia, se debe garantizar la integridad física, psíquica y moral de las mujeres frente a la agresión del marido, del padre o padrastro, los hermanos y otros miembros del entorno familiar (tíos, etc.). Además, la integridad física debe ser garantizada frente a la agresión de las parejas. Del mismo modo, debe asegurarse el igual acceso a la alimentación, asistencia de salud y educación que el varón, en lo que a la familia le corresponda.

Respecto a las iglesias, debe garantizarle la integridad física, psicológica y moral de las mujeres al interior de la comunidad de creyentes. Además debe de asegurar la igualdad entre hombres y mujeres frente a la posibilidad de ocupar cargos de autoridad dentro de sus respectivas iglesias.

\section{5.- JUSTICIA Y SEXUALIDAD HUMANA}

La justicia respecto a las mujeres trae consigo la cuestión de la justicia respecto de las minorías sexuales dentro de la sociedad, a nivel político y social. Esto supone una amplia comprensión de la sexualidad humana que permita cuestionar el discurso que considera que las minorías sexuales expresan desviaciones o enfermedades psíquicas. Esto supone abrir el espacio para que las personas puedan reflexionar respecto de su autorrelación práctica. Esto supone abandonar la creencia difundida de que las minorías sexuales representan desviaciones o enfermedades, para pasar a comprender que cada persona descubre y define su orientación sexual por medio de una reflexión respecto a su relación con su propia corporeidad.
Esto supone, además, incluir en la reflexión social la experiencia antropológica e histórica comparada, para cuestionar la tradicional opinión respecto de lo natural en la sexualidad humana. Por ejemplo, en la cultura griega, la homosexualidad no resultaba problemática. Es más, los griegos consideraban que esa clase de relación era superior a la del hombre-mujer, porque se trataba de una relación entre iguales (cf. Nussbaum 1997). En El Banquete, Platón emprende justamente la defensa de la relación homosexual. Los argumentos de Platón son claros al respecto: la relación heterosexual tiene como finalidad la procreación en vista a la preservación física de la especie. Pero dicho fin es imperfecto porque se conecta con una valoración de lo sensible y temporal de la realidad. En cambio, la relación homosexual es superior porque ella permite el perfeccionamiento del alma, la cual se conecta con el ámbito eterno de la realidad. Así, en el texto de Platón, Sócrates señala que Diotima le ha indicado no sólo el origen de Eros, sino que es un semidios y que el amor más perfecto es entre dos hombres:

"... losquesonfecundos-dijo- según el cuerpo se dirigen perfectamente a las mujeres y de esta manera son amantes, procurándose mediante la procreación de los hijos inmortalidad, recuerdo y felicidad, según creen, para todo el tiempo futuro. En cambio, los que son fecundos según el alma...pues hay, en efecto -dijo-, quienes conciben en las almas aún más que en los cuerpos lo que corresponde al alma concebir y dar a luz ¿Y qué es lo que le corresponde? En conocimiento y cualquier otra virtud, de las que son precisamente procreadores todos los poetas y cuantos artistas 
se dice que son inventores. Pero el conocimiento mayor y más bello es, con mucho, la regulación de lo que concierne a las ciudades y familias, cuyo nombre es mesura y justicia. Ahora bien, cuando uno de estos se siente desde joven fecundo en el alma, siendo de naturaleza divina y, llegada la edad, desea ya procrear y engendrar, busca entonces también él , creo yo, en su entorno la belleza en la que pueda engendrar, pues en lo feo nunca engendrará. Así, pues, en razón de su fecundidad, se apega más a los cuerpos bellos que a los feos, y si tropieza con un alma bella, noble y bien dotada por naturaleza, entonces muestra un gran interés por el conjunto; ante esa persona tiene al punto abundancia de razonamientos sobre la virtud, sobre cómo debe ser el hombre bueno y lo que debe practicar, e intenta educarlo. En efecto, al estar en contacto, creo yo, con lo bello y tener una relación con ello, da a luz y procrea lo que desde hace tiempo tenía concebido, no sólo en su presencia, sino recordándolo en su ausencia, y en común con el objeto bello ayuda a criar lo engendrado, de tal suerte que los de tal naturaleza mantienen entre sí una comunidad mucho mayor que la de los hijos y una amistad más sólida, pues tienen en común hijos más bellos y más inmortales. Y todo el mundo preferiría para sí haber engendrado tales hijos en lugar de los humanos..." (Platón 2010, p. 110-111).

Como vemos, para Platón -como para sus contemporáneos griegos- la homosexualidad no resultaba ser un problema. Más bien, lo que consideraban humillante es la posición del pasivo en la relación. En otras culturas la actitud frente a la homosexualidad es otra, no necesariamente de rechazo como en el mundo cristiano. En nuestra cultura occidental contemporánea sucede que estudiar la historia de la sexualidad humana suscita controversias y levanta grandes impedimentos. Razón por la cual no hay se incluye en los currículos académicos de las universidades y no se encuentra mucha bibliografía sobre el tema. No sucede lo mismo con otros estudios históricos, como el de la esclavitud y la persecución religiosa. Tal como lo señala Martha Nussbaum, en los últimos casos consideramos que esa clase de estudios ayudan a clarificar nuestro juicio moral, en cambio respecto de la historia de la sexualidad humana tenemos la creencia que el efecto es el contrario, a saber, lo enturbiará. Y es que esta clase de estudios lo que hace es confrontar nuestras acciones y creencias, aunque "parece poco claro por qué el aprendizaje de los diferentes modos que la gente tiene de pensar sobre el sexo debería erosionar todo juicio moral bien fundado" (Nussbaum 2005, p. 235).

La idea de que sexualidad humana es una "construcción social" más que un dato objetivo de la realidad ha sido sostenida por Michel Foucault (1995). Pero el trabajo de Foucault, por haber sido asociado con una posición extrema, ha sido desestimado. Este tipo de trabajos se asocia a una agenda radical que se dirige a subvertir los valores morales habituales. Pero esa asociación no permite analizar el argumento en sí y ver su relación con argumentos morales normativos. Nussbaum sostiene acertadamente que la mejor manera de comprender el argumento de la "construcción social" respecto de la sexualidad humana es analizando lo que sucede con las emociones (como el miedo, la pena, la cólera, la envidia, el celo, el amor, entre otras parecidas). "Tales emociones no son simplemente 
datos de nuestra constitución biológica (aunque podrían tener una base biológica): implican una buena cantidad de aprendizaje. Otro postulado es que este aprendizaje ocurre en la sociedad y es conformado de manera decisiva por la sociedad" (Nussbaum 2005, p. 240$241)^{2}$. De la misma manera, la sexualidad humana es construida socialmente. Pero esta conclusión no nos conduce necesariamente a la posición radical de Foucault según la cual lo que corresponde, como consecuencia, es llevar adelante un cuestionamiento radical y una subversión de nuestros juicios morales. Al contrario, el comprender que la sexualidad se encuentra en gran medida construida socialmente, nos puede conducir a la clarificación de nuestros juicios morales.

Se me preguntará cuál es la pertinencia de tratar el tema de la sexualidad humana en un ensayo dedicado a la justicia respecto a la mujer. La razón es la siguiente: los enfoques respecto de la mujer, como los referentes a la familia y otros afines pierden el horizonte que los hace comprensibles de una mejor manera si no se enmarcan en un debate en torno a la sexualidad humana en general. El enfoque de la sexualidad humana otorga las herramientas conceptuales necesarias para discutir temas, como los roles tradicionales de la mujer o la emancipación de las mujeres, respecto de la sujeción ante el varón. Además, es posible esgrimir un argumento adicional, siguiendo la línea de investigación iniciada por John Stuart Mill. Si las opiniones extendidas eran el único argumento para sostener que los negros eran esclavos "por naturaleza" y que las mujeres debían estar sometidas al varón "por naturaleza", no sería consistente si no se pudiese extender también al caso de las minorías sexuales, y no fuese posible señalar que el trato que les damos a ellas en nuestra cultura contemporánea no se basa en un argumento fundado en la "naturaleza", sino más bien en opiniones extendidas, es decir, en construcciones sociales. Resultaría arbitrario señalar que el argumento de Mill funciona para las mujeres pero no para las minorías sexuales.

\section{6.- CONCLUSIONES}

La reflexión respecto de la conexión entre la justicia liberal y las mujeres suponen asumir una versión del liberalismo que incluya necesariamente la voz de las mujeres al momento de debatir la modelación de las instituciones políticas y morales. Para ello es importante dotar a las mujeres de una educación adecuada, y de criterios e información relevantes para poder participar con claridad en los debates y permitir que su voz sea escuchada. El poco acceso a la educación, hace que en muchos sectores del planeta la situación de las mujeres no haya variado sustantivamente que la consignada por John Stuart Mill en el siglo XIX.

Por otro lado, el enfoque del feminismo posmoderno no sólo parte de premisas cuestionables, como la que pretende extraer consideraciones morales de datos biológicos. Sino que, además, no permite dar cuenta de las ausencias de libertades que sufren las mujeres. Es por ello, que la perspectiva liberal sensible a la voz de las mujeres

2 Respecto de la construcción de los sentimientos, Aristóteles, en el libro II de su Retórica los afectos siempre son sentimientos de placer o displacer que se construyen sobre un juicio de valor. Así, el temor es un sentimiento de displacer cuando somos conscientes de que un acontecimiento futuro pondrá en peligro nuestro bienestar. Al respecto, ver TUGENHAT (1997). De esta manera, el argumento que sostiene que los sentimientos o las emociones son construcciones adquiere fuerza. 
en la definición de los daños se presenta como un enfoque más apropiado, pues permite tener información más relevante respecto de los tipos de libertades conculcadas a las mujeres.

Un elemento adicional que resulta ser importante para ampliar el enfoque es enfrentar el problema de la justicia para con las minorías sexuales, pues es la única manera de derribar la opinión extendida según la cual existiría una naturaleza humana, opinión que en realidad encierra prejuicios ancestrales. De no hacer eso, la justicia para con la mujer siempre encontrará sus límites. Pero además, la justicia respecto de las minorías sexuales no tiene sólo ese valor instrumental, sino que también tiene un valor en sí misma. Para alcanzar ambas cosas, las teorías feministas clásicas terminan mostrando sus límites, pues no logran despercudirse de ciertos esencialismos que podrían conducir a relaciones de subordinación y de discriminación injusta. En este sentido, resulta importante comprender que la sexualidad humana es una construcción social, más que un dato biológico.

\section{REFERENCIAS:}

BENDER, T. (2011) Historia de los Estados Unidos. Una nación entre naciones. Madrid: Siglo XXI.

BENHABIB, S. (2006). El ser y el otro en la ética contemporánea: feminismo, comunitarismo y posmodernismo. Barcelona: Gedisa.

FOUCAULT, M. (1995) Historia de la sexualidad. Buenos Aires: Siglo XXI.

FRASER, N. (2008) Escalas de la justicia. Barcelona: Herder.

FRASER, N. (1997) Iustitia Interrupta. Reflexiones críticas desde la posición "postsocialista". Bogotá: Universidad de los Andes.

GILLIGAN, C. (1994) La moral y la teoría: psicología del desarrollo femenino. MÉXICO: Fondo de Cultura Económica.

MILL, J. S. (2005) El sometimiento de las mujeres. Madrid: Edaf.

NUSSBAUM, M. (2012) Crear capacidades. Barcelona: Paidós.

NUSSBAUM, M. (2005) El cultivo de la humanidad. Una defensa clásica de la reforma de la educación liberal, Barcelona: Paidós.

NUSSBAUM, M. (2012) Las mujeres y el desarrollo humano. Barcelona: Herder.

O'NEILL, O. (1996) "Justicia, sexo y fronteras internacionales". En SEN, A. y NUSSBAUM, M. Calidad de vida. México: FCE.

PLATÓN (2010) El Banquete. Madrid: Gredos.

RAWLS, J. (1996) Liberalismo político. México: FCE.

RAWLS, J. (2001) El derecho de gentes y "una revisión de la idea de razón pública". Barcelona: Paidós.

RORTY, R. (2000) "Feminismo y pragmatismo". En RORTY, Richard; Verdad y progreso Escritos filosóficos 3, Barcelona: Paidós.

TUGENDHAT, E. (1997) Lecciones de ética. Barcelona: Gedisa.

WALZER, M. (2010) "El liberalismo y el arte de la separación". En WALZER, M. Pensar políticamente. Madrid: Paidós. 